\title{
CRESCIMENTO INICIAL DE EUCALIPTO COM INCORPORAÇÃO DE PÓ DE ROCHA POTASSICA EM LATOSSOLO VERMELHO AMARELO
}

\section{INITIAL GROWTH OF EUCALYPTUS WITH THE INCORPORATION OF POTASSIUM ROCK POWDER IN YELLOW RED LATOSOL}

\author{
Tainá Paula Laurindo dos Santos ${ }^{1}$; Paloma Cunha Saraiva ${ }^{2}$; Ayrton Senna da Silva \\ Damasceno $^{3}$; Breendon Patrick da Silva Gonçalves ${ }^{4}$; Cácio Luiz Boechat ${ }^{5}$
}

DOI: $\underline{\text { https://doi.org/10.31692/978-65-991061-7-0.392-396 }}$

\section{INTRODUÇÃO}

A expansão das áreas de florestas plantadas e o crescente consumo de matéria-prima florestal tem requerido maior demanda por mudas de espécies florestais. Não obstante a isso, a preocupação com a qualidade dessas mudas vem aumentando, pois garante a sobrevivência no campo e diminui os custos de implantação florestal (FONSECA, 2012).

A obtenção de mudas de boa qualidade exige a utilização de substrato que forneçam os nutrientes necessários ao pleno desenvolvimento da planta (CECONI et al., 2007), sendo que o substrato é o meio em que as raízes se desenvolvem fornecendo suporte estrutural e também concentrações necessárias de água e oxigênio (CARNEIRO, 1995).

Nesse sentido, visando reduzir o custo de produção e os impactos negativos na balança comercial brasileira, no que se refere ao uso de adubos químicos, algumas tentativas têm sido feitas para utilizar rochas in natura diretamente no solo (LOPES-ASSAD, 2006), reduzindo a utilização de adubos de maneira indiscriminada e pouco racional que é um dos problemas que comprometem a sustentabilidade do solo e do meio ambiente.

A aplicação de fertilizantes naturais como o pó-de-rocha tem muitas vantagens, destacando-se a taxa de dissolução das rochas e dos minerais, e a reação entre superfícies minerais e a solução do solo, que são intensificadas em função da temperatura e da umidade (VAN STRAATEN, 2006). Diante do exposto, objetivou-se avaliar a utilização de resíduo inorgânico como fonte alternativa de potássio na nutrição do híbrido de Eucalyptus tereticornis x Eucalyptus urophylla.

\section{FUNDAMENTAÇÃO TEÓRICA}

O método de regeneração da fertilidade do solo, impulsionado com a Revolução

\footnotetext{
${ }^{1}$ Graduanda em Engenharia Florestal, UFPI-CPCE, E-mail: tainalaurindoo@ outlook.com

${ }^{2}$ Engenharia Florestal, UFPI-CPCE, E-mail: paloma-saraiva31@ hotmail.com

${ }^{3}$ Mestrando em Fitotecnia, UFPI-CPCE, E-mail: ayrtondamasceno12@gmail.com

${ }^{4}$ Engenheiro Florestal, E-mail: breendonpsg@ hotmail.com

${ }^{5}$ Prof. Adjunto do curso de Engenharia Agronômica, UFPI-CPCE, E-mail: cacioboechat@gmail.com
} 
Verde, é baseado no emprego de adubos minerais de alta solubilidade e revela-se inviável para a ampla maioria das famílias agricultoras em função de seu alto custo e dos impactos ambientais negativos gerados (ALMEIDA et al., 2007).

Visto que essa problemática ambiental tem despertado nos últimos anos grande interesse no Brasil e os custos de disposição de resíduos de forma ecologicamente correta são elevados (MOREIRA et al., 2005). Isto tem motivado a busca de alternativas tecnológicas viáveis, visando reduzir gastos na produção, e os impactos negativos na balança comercial brasileira, no que se refere ao uso de adubos químicos, assim, algumas tentativas têm sido feitas para utilizar rochas in natura diretamente no solo.

Melamed et al. (2007) destacam que os benefícios advindos da utilização de pós de rocha são: o fornecimento lento de macro e micronutrientes; aumento da disponibilidade desses nutrientes nos solos cultivados; reequilíbrio do $\mathrm{pH}$ do solo e aumento da reserva nutricional do solo. Estudos realizados por Knapik \& Ângelo (2005), com a adição de rocha triturada ao solo para fins de adubação agrícola tem mostrado resultados satisfatórios para algumas culturas.

\section{METODOLOGIA}

O experimento foi desenvolvido em casa de vegetação a 50\% de sombra no município de Bom Jesus-PI, utilizando-se o clone de Eucalyptus tereticornis $x$ Eucalyptus urophylla (KL 104), concedidos pela empresa Eco Empreendimentos.

O solo utilizado foi coletado na profundidade de $0-20 \mathrm{~cm}$ e classificado como Latossolo Amarelo de textura arenosa, de acordo com o Sistema Brasileiro de Classificação de Solo. O pó de rocha potássica foi coletado em uma mina com formação rochosa sedimentar com elevada concentração potássica, no município de Corrente, Piauí.

Os tratamentos foram dispostos em um delineamento experimental em blocos casualizados (DBC), com quatro repetições. Os tratamentos foram T1: Testemunha (apenas solo); T2: $1 \mathrm{Mg} \mathrm{ha}^{-1}$ de pó de rocha; T3: $10 \mathrm{Mg} \mathrm{ha}^{-1}$ de pó de rocha; T4: $15 \mathrm{Mg} \mathrm{ha}^{-1}$ de pó de rocha; T5: $30 \mathrm{Mg} \mathrm{ha}^{-1}$ de pó de rocha e T6: Adubação recomendada de N-P-K $\left(\mathrm{g} \mathrm{Kg}^{-1}\right)$ para a cultura de eucalipto.

Duas mudas de eucalipto foram transplantadas com seus respectivos tratamentos para unidades experimentais (UE) vasos com volume de 4 L. O desbaste das mudas foi realizado 30 dias após a implantação, permanecendo a muda visualmente mais vigorosa por recipiente. A irrigação foi realizada periodicamente a fim de manter a mistura com umidade próxima a $70 \%$ da capacidade de campo do solo. 
Aos 90 dias após o desbaste foram avaliadas as variáveis morfologicas: comprimento da parte aérea (CPA), diâmetro do colo (DC), massa fresca da parte aérea (MFPA), massa seca e da parte aérea (MSPA), e calculados os índices de qualidade de mudas: Índice de qualidade de Dickson (IQD), a relação entre o comprimento da parte aérea e o diâmetro do colo (RHDC), a relação entre o comprimento da parte aérea e o peso de matéria seca da parte aérea (RHMSPA), a relação entre o peso de matéria seca da parte aérea e o peso de matéria seca das raízes (RPPAR).

Os dados foram submetidos à análise de variância (ANOVA) pelo teste F, e as médias, quando significativas, submetidas ao teste de Tukey a 5\% de probabilidade empregando-se o programa estatístico SISVAR (FERREIRA, 2011).

\section{RESULTADOS E DISCUSSÕES}

Observaram-se diferenças significativas entre as médias dos tratamentos para todas as variáveis e parâmetros, conforme os resultados apresentados na Tabela 1, exceto para a relação CPA/DC. A adição de pó de rocha potássico condicionou incrementos em altura e diâmetro (CPA e DC) quando comparados ao tratamento testemunha (T1), não se observando diferenças significativas entre as demais doses de pó de rocha potássica.

Tabela 1. Comprimento da parte aérea (CPA), diâmetro do coleto (DC), massa fresca da raiz (MFR), massa seca da parte aérea (MSPA), massa seca da raiz (MSR), ), Indíce de Qualidade de Dickson (IQD), relação entre a

altura da parte aérea e o diâmetro do coleto (CPA/DC) relação entre a altura e massa seca da parte aérea (CPA/MSPA) de clones de Eucalyptus urophylla x tereticornis cultivados em Latossolo sob proporções de pó de rocha.

\begin{tabular}{|c|c|c|c|c|c|c|c|}
\hline \multirow{2}{*}{ Tratamentos } & $\mathrm{CPA}$ & $\mathrm{DC}$ & MSPA & MSR & IQD & CPA/DC & CPA/MSPA \\
\hline & $\mathrm{cm}$ & $\mathrm{mm}$ & \multicolumn{2}{|c|}{$\mathrm{g}$} & - & - & \\
\hline $\mathrm{T} 1$ & $49,6 b$ & $4,23 b$ & $4,95 b$ & $3,10 \mathrm{~b}$ & $0,60 \mathrm{~b}$ & $11,74 \mathrm{a}$ & $1,59 b$ \\
\hline $\mathrm{T} 2$ & $70,42 \mathrm{a}$ & $7,28 \mathrm{a}$ & $19,77 \mathrm{a}$ & $7,83 \mathrm{a}$ & $2,26 \mathrm{a}$ & $9,69 \mathrm{a}$ & $2,5 \mathrm{a}$ \\
\hline $\mathrm{T} 3$ & $63,2 \mathrm{a}$ & $5,955 a$ & $9,46 b$ & $3,93 b$ & $1,07 \mathrm{~b}$ & $10,94 a$ & $2,53 \mathrm{a}$ \\
\hline $\mathrm{T} 4$ & $63,65 \mathrm{a}$ & $6,77 \mathrm{a}$ & $17,23 \mathrm{a}$ & $6,59 a$ & $1,65 \mathrm{a}$ & $9,50 \mathrm{a}$ & $2,62 \mathrm{a}$ \\
\hline $\mathrm{T} 5$ & $67,25 a$ & $6,802 \mathrm{a}$ & $15,51 \mathrm{a}$ & $5,34 \mathrm{a}$ & $1,62 \mathrm{a}$ & $9,97 \mathrm{a}$ & $2,98 \mathrm{a}$ \\
\hline N-P-K & $65,925 a$ & $6,08 \mathrm{a}$ & $13 \mathrm{a}$ & $5,62 \mathrm{a}$ & $1,43 \mathrm{a}$ & $10,88 \mathrm{a}$ & $2,36 \mathrm{a}$ \\
\hline $\mathrm{CV}(\%)$ & 8,23 & 9,26 & 29,25 & 28,78 & 28,72 & 9,65 & 22,76 \\
\hline
\end{tabular}

T1: Testemunha (apenas solo); T2: $1 \mathrm{Mg} \mathrm{ha}^{-1}$ de pó de rocha; T3: $10 \mathrm{Mg} \mathrm{ha}^{-1}$ de pó de rocha; T4: 15 $\mathrm{Mg} \mathrm{ha}^{-1}$ de pó de rocha; $\mathrm{T} 5: 30 \mathrm{Mg} \mathrm{ha}^{-1}$ de pó de rocha e T6: Adubação recomendada de N-P-K $\left(\mathrm{g} \mathrm{Kg}^{-}\right.$ $\left.{ }^{1}\right)$. Médias seguidas de mesma letra na coluna não diferem entre si pelo teste de Tukey $(\mathrm{p}<0,05)$.

As variáveis relacionadas a biomassa da parte aérea e da raiz (MSR), também não 
houveram diferenças entre os tratamentos, exceto T3 e T1 (10 $\left.\mathrm{Mg} \mathrm{ha}^{-1}\right)$, que apresentaram os menores valores para esta variável em relação aos demais tratamentos (Tabela 1). Carneiro (1995), afirma que os maiores valores para a massa seca da raiz são indicadores de maior porcentagem de sobrevivência no campo, uma vez que a presença de raízes fibrosas permite maior capacidade de as mesmas manterem-se em crescimento e de formação de raízes novas, mais ativas, possibilitando maior resistência em condições extremas.

Para a variável IQD, não observou -se diferença estatística entre as médias dos tratamentos, exceto para testemunha (T1) e com a adição de $10 \mathrm{Mg} \mathrm{ha}^{-1}$ (T3), apresentando os menores índice para o parâmetro (Tabela 1). Segundo Fonseca (2000) este parâmetro é bom indicador da qualidade das mudas, pois considera para o seu cálculo a robustez e o equilíbrio da distribuição da biomassa da muda, sendo ponderados vários parâmetros considerados importantes (FONSECA, 2000). Desde modo a adição do pó de rocha ao substrato trouxe efeitos satisfatórios no crescimento das mudas.

Os maiores índices para a relação CPA/MSPA foram obtidos apenas nos tratamentos com a aplicação de pó rocha, não sendo observadas diferença significativas para o mesmo, somente na testemunha (T1), o qual obteve menor valor para o índice (Tabela 1). Este quociente obtido pela divisão CPA pela MSPA pode predizer o potencial de sobrevivência da muda no campo, verificando que quanto menor for esse índice mais lenhificada será a muda e maior deverá ser a sua capacidade de sobrevivência no campo (GOMES 2001).

\section{CONCLUSÕES}

A adição do resíduo inorgânico pó de rocha potássica pode ser utilizado como fonte alternativa de potássio na produção de mudas de eucalipto em doses maiores que $10 \mathrm{t} \mathrm{ha}^{-1}$.

\section{REFERÊNCIAS}

ALMEIDA, E.; SILVA, F.J.P.; RALISCH, R. Revitalização dos solos em processos de transição agroecológica no Sul do Brasil. Revista Agriculturas: Experiências em Agroecologia, Rio de Janeiro, v.4, n.1, p.7-10, 2007.

CECONI, D. E.; POLETTO, I.; LOVATO, T.; MUNIZ, M. F. B. Exigência nutricional de mudas de erva-mate (Ilex paraguariensis A. St.-Hil.) à adubação fosfatada. Ciência Florestal, v. 17, n. 1, p. 25-32, 2007.

CARNEIRO, J. G. A. Produção e controle de qualidade de mudas florestais. Universidade Federal do Paraná, Curitiba, PR (Brasil) Universidade Estadual do Norte Fluminense, Campos, RJ (Brasil) Fundação de Pesquisas Florestais do Paraná, Curitiba, PR (Brasil), 1995.

GOMES, J.M. Parâmetros morfológicos na avaliação da qualidade de mudas de 
Eucalyptus grandis, produzidas em diferentes tamanhos de tubete e de dosagens de N-PK. p. 126. Tese (Doutorado em Ciência Florestal). Universidade Federal de Viçosa, Viçosa, 2001.

FERREIRA, D.F. Sisvar: A computer statistical analysis system. Ciência e Agrotecnologia, v.35, n.6, p.1039-1042, 2011.

FONSECA, M. D. S. Influência do tamanho do recipiente na qualidade de mudas de três espécies de eucalipto. 2012. 49 f. Trabalho de Conclusão de Curso (Graduação em Engenharia Florestal)- Universidade Federal do Recôncavo Baiano, Cruz das Almas, 2012.

KNAPIK, J. G.; ANGELO, A. C. Pó de basalto e esterco equino na produção de mudas de Prunus sellowii Koehne (ROSACEAE). Floresta, v. 37, n. 03, p. 427-436, 2007.

LOPES-ASSAD, M. L.; ROSA, M. M.; ERLER, G.; CECCATO-ANTONINI, S. R. Solubilização de pó-de-rocha por Aspergillus niger. Espaço \& Geografia, v. 9, n. 1, p. 1-17, 2006.

MELAMED, R.; GASPAR, J.C.; MIEKELEY, N. Pó-de-rocha como fertilizante alternativo para sistemas de produção sustentáveis em solos tropicais. (Série estudos e documentos, 72). Disponível em: 〈http://www.cetem.gov.br/serie_sed.htm〉. Acesso em: 09 jul. 2007.

MOREIRA, J. M. S.; MANHÃES, J. P. V. T.; HOLANDA, J. N. F. Reaproveitamento de resíduo de rocha ornamental proveniente do Noroeste Fluminense em cerâmica vermelha.(Utilization of ornamental rock waste from Northwest Fluminense in red ceramic). Revista Cerâmica, v. 51, n. 319, p. 180-186, 2005.

VAN STRAATEN, P. Farming with rocks and minerals: challenges and opportunities. Anais da Academia Brasileira de Ciências, v. 78 (4): p. 731-747, 2006. 